\title{
EVALUATION OF THE PERFORMANCE OF PHARMACISTS IN TERMS OF PROVIDING HEALTH ASSISTANCE AT A UNIVERSITY HOSPITAL
}

\author{
Thaís Rodrigues Penaforte ${ }^{1}$, Aldaisa Cassanho Forster ${ }^{2}$, Maria Jacira Silva Simões ${ }^{3}$
}

Penaforte TR, Forster AC, Silva MJS. Evaluation of the performance of pharmacists in terms of providing health assistance at a university hospital. Clinics. 2007;62(5):567-72.

OBJETIVE: This study aimed to assess the practices of pharmacists in Hospital Care. Method - we interviewed 20 pharmacists from the Pharmacy Division by applying a structured instrument, in September 2005. This instrument addressed aspects related to the main activities at the Hospital Pharmacy, which were assessed according to indicators organized into five areas: sector management, hospital pharmacotechniques, committee activities, information and pharmacotherapeutic follow-up, as well as teaching and research activities.

RESULTS: The Pharmacy Division considered all structural aspects under analysis as essential for the good development and application of its services. We found that some essential services, such as the Medication Information Service and Pharmacotherapeutic Follow-up, were absent. Pharmacist professionals were dissatisfied about human resource and physical structure dimensioning, and they presented as not very active in terms of Pharmaceutical Care.

CONCLUSION: Results indicate that care is still centered on the drug, with few clinical activities. We suggest reformulations in service management, particularly in the management of pharmacists.

KEY-WORDS: Hospital Pharmacy Service. Process and Result Assessment (Health Care). Hospital Human Resources Administration. Health Care Quality. Hospital Pharmacist.

\section{INTRODUCTION}

The Hospital Pharmaceutical Assistance is a complex and relevant system within the management of health systems and services not only because it represents one of the basic instruments for patient care, but also because of the high costs it involves. ${ }^{1}$

The main function of the Hospital Pharmacy (HP) is to guarantee the quality of patient care by means of the safe and rational use of medications and correlates, adapting

\footnotetext{
${ }^{1}$ University of São Paulo, College of Medicine of Ribeirão Preto, Department of Social Medicine/Ribeirão Preto, Brazil

${ }^{2}$ University of São Paulo, College of Pharmaceutical Sciences of Ribeirão Preto/ Ribeirão Preto, Brazil

${ }^{3}$ São Paulo State University - College of Pharmaceutical Sciences, Araraquara/Brazil

Email: thaispenaforte@terra.com.br

Received for publication on April 18, 2007

Accepted for publication on June 18, 2007
}

their application to individual and collective health on the assistance, prevention, teaching and investigative planes. ${ }^{2}$

Among the many challenges faced by the HP is the management of Human Resources since the quality and the efficiency of Hospital Pharmaceutical Assistance is directly conditioned to structure, to the work process, to the human resources, and to the appropriate use of medications.

Thus, the objective of the present study was to evaluate the practices of Pharmaceutical Assistance of Pharmacists within Hospital Assistance as a whole in order to obtain better information about the performance of both the HP and of its pharmacists, in addition to providing data to be used as reference for the elaboration of priorities and strategies for the development and improvement of the Pharmacy Division.

\section{METHOD}

The area of evaluation of programs, services and tech- 
nologies represents a field of production of knowledge and practices and clearly and acutely experiences the difficulties faced by those who try to provide such evaluation regarding the identification of the conditions necessary for the construction of knowledge, which is a product of a theoretical nature, and by those who organize its transformation into practices, which are always of a concrete nature. ${ }^{3}$

Since this was an investigation regarding the Management of Health Services, among the definitions existing for evaluation, we adopted the approach proposed by Donabedian ${ }^{4}$ as well as the concepts of Patton. ${ }^{5}$

According to Donabedian, when health care is to be evaluated the approach used concerns:

- Structure (physical and organizational properties of the environment in which care is provided);

- Process (what is done for the patients);

- Result (what is finalized for the patients).

According to Patton, evaluation involves the systematic collection of information about the activities, characteristics and results of programs, human resources and products available to specific persons in order to reduce uncertainties, to increase effectiveness and to make decisions regarding what these programs, human resources and products are doing or affecting. ${ }^{6}$

The subjects of the present investigation were the 20 pharmacists working in the Pharmacy Division of the Hospital under study. With one abstention (1/20), was obtained a total number of subjects as being: 19 pharmacists. All were contacted personally or by telephone and, after a brief explanation of the study was given, an interview was scheduled.

A structured instrument (Table 1) was applied to all pharmacists, containing aspects regarding the description of the activities executed related to the main activities of the HP (Table 2), systematically presented on an Excel spreadsheet.

The indicators selected were those which characterize the main activities to be carried out inside the HP.

The study was approved by the Research Ethics Committee of the Hospital under study and all persons interviewed participated voluntarily in the study and signed a free and informed consent form according to resolution CNS 196/96 of the National Council of Health. The identity of the interviewees was preserved, as also was the anonymity of the information.

\section{RESULTS}

The activities analyzed in the present study were subdivided into two categories: The Essential Services to be supplied by the Hospital Pharmacy and the Activities re-
Table 1 - Questions included in the research instrument

\section{Characterization of the Hospital Pharmacy}

Responsible Pharmacist Technician for the HPNumber of Pharmacists Number of employees (assistants and technicians)

Location: (specify in detail)

Is the location of the pharmacy satisfactory?

Does it facilitate the dispensing of medications to the patients?

Does it facilitate the distribution of medications and $\mathrm{MMH}$ ?

Which hospital services or areas are contiguous to any of the areas of the sector responsible for the medications?

Questions regarding the logistics of the HP

Do you participate in the purchase of medications?

Do you participate in the bidding committee?

Do you participate in the elaboration of technical specifications for the purchase of medications?

Are you in contact with the ABC curve of the HP?

Questions regarding the dispensation of medications

Do you check the medical prescription?

What type of medical prescription is handled by your sector?

What type of preparation do you execute?

Are you involved in the quality control of the preparations?

What do you think of the structure in which you manipulate your preparations?

Do you think that inadequacy of the structure impairs the execution of your work?

Do you participate in some hospital committee? What is the frequency of the meetings? How much time did you spend in the last meeting? Do you participate in activities related to pharmacoeconomy?

Do you participate in the elaboration of therapeutical protocols? Do you participate in the elaboration of the Pharmacotherapeutic guide? Do you provide information about medications to the hospital community? Do you have a written record of the requests you receive for information about medications?

Do you participate in educational activities with the patients?

Do you participate in medical visits or do you pay specific visits to the patients?

Do you perform pharmaceutical consultation with pharmacotherapeutic follow-up of the patients?

Do you participate in activities of Pharmacotherapeutic Monitoring of the patients?

Questions Related to Teaching and Research

Do you participate in educational and training activities within the hospital Do you participate in research activities within the hospital?

Table 2 - Components of the Hospital Pharmacy

\begin{tabular}{ll}
\hline $\begin{array}{l}\text { Essential services supplied } \\
\text { by the Hospital Pharmacy Service }\end{array}$ & $\begin{array}{l}\text { Activities related to the operational } \\
\text { structure of the Pharmacy Service }\end{array}$ \\
\hline Teaching and Research & Medication Dispensing \\
Committee activities & LogisticsManagement \\
$\begin{array}{ll}\text { Information and Pharmaceutical } \\
\text { Care }\end{array}$ & Selection of Medications \\
& Distribution \\
& Hospital Pharmacotechnique \\
\hline
\end{tabular}

Source $^{10}$ 
lated to the operational structure of the Pharmacy Service

\section{Essential services to be supplied by the Hospital Pharmacy Service}

\section{Teaching and Research}

It was obtained that $95 \%$ of the pharmacists (18/19), affirmed to participate in activities of Teaching and Research. However this participation is restricted to contact with Hospital Pharmacy trainees, and considering the year 2004; as reference, there was no scientific production by any of the pharmacists interviewed.

\section{Committee activities}

The pharmacists participated in all the main committees requiring compulsory pharmacist participation (Pharmacy and Therapeutics Committees, Nutritional Support Committee, Hospital Infection Control Committee), although a more active participation was observed only in the Nutritional Support Committee.

\section{Information and Pharmacotherapeutic Monitoring}

Eighty-nine percent of the pharmacists (17/19), stated that provide information about the medications to the hospital community. However, this procedure was not accomplished in a systematic manner, with no specific forms or written records of these requests being used, and with the absence of a center organized for this purpose. None of the pharmacists interviewed execute activities of Pharmacotherapeutic Monitoring of the patients.

\section{Activities related to the operational structure of the Pharmacy Service}

\section{Medication Dispensing}

Ninety-five percent of the professionals (18/19) stated that evaluated the medical prescriptions according to the items listed in Table 3.

\section{Logistics}

Regarding the management of the units, $89 \%$ of the pharmacists (17/19) were responsible for the control of the stock of their sector, $31 \%(6 / 19)$ participated in the purchasing of the medications, and only $10 \%(2 / 19)$ participated in the bidding committee. The ABC curve for the determination of priorities regarding the decision making process related to the acquisition of medications was not used by $68 \%$ (13/19) of the pharmacists.

\section{Hospital Pharmacotechnique}

Fifty-eight percent of the pharmacists (11/19) work in the Pharmacotechnique Sector. Table 4 presents the types of preparations executed.

The quality control protocols were applied only to Intravenous Mixtures and to Parenteral Nutrition. Regarding the premises where the preparations are executed, 100\% of the pharmacists (19/19) considered the structure inadequate and, $89 \%(17 / 19)$ considered this inadequacy impair the execution of their work.

Table 3 - Distributions of the items analyzed in the medical prescription according to the pharmacists, 2005

\begin{tabular}{lcc}
\hline Item & $\mathrm{n}$ & $\%$ \\
\hline Dosage & 15 & 29 \\
Medication & 3 & 6 \\
Patient Identification & 2 & 4 \\
Posology & 6 & 11 \\
Pharmaceutical form & 3 & 6 \\
Route of administration & 5 & 10 \\
Obeying clinical protocols & 3 & 6 \\
Time of treatment & 1 & 2 \\
Concentration of the items prescribed & 3 & 6 \\
Totality of the prescription & 1 & 2 \\
Prescribed with a generic name & 1 & 2 \\
Identification of the prescribing physician & 3 & 6 \\
Incompatibility and/or interaction among the components & 2 & 4 \\
Quantity of the medications & 3 & 6 \\
\hline Total & 51 & 100 \\
\hline
\end{tabular}

Table 4 - Types of preparations manipulated at the Hospital Pharmacy, 2005

\begin{tabular}{lcc}
\hline TYPE OF PREPARATION & $\mathrm{n}$ & $\%$ \\
\hline Chemotherapy & 4 & 37 \\
Intravenous Mixtures & 1 & 09 \\
Parenteral Nutrition & 3 & 27 \\
Non-sterile Mixtures & 3 & 27 \\
\hline TOTAL & 11 & 100 \\
\hline
\end{tabular}

\section{DISCUSSION}

A study carried out at the University of Otago in New Zealand to evaluate the perception and the barriers faced by the pharmacist regarding pharmaceutical practice demonstrated that $60 \%$ of these professionals believe that the future of pharmacy resides in the services provided by the pharmacists and not simply in the dispensing of medications, ${ }^{7}$ that is, they believe that there is an urgent need to modify the centralization of pharmaceutical-hospital care around the medications and to direct it at human resources, represented both by the professionals who provide the services and by the patients who benefit from them. 
The organization of a service is related to the functionality of the services it provides and its objective is an efficient and effective management. To this end, a good dimensioning of activities is indispensable, with their optimization by means of an efficient division of tasks among the components of the team.

Research and Teaching activities are considered to be of priority within the activities related to the HP. Their function within a school hospital becomes more important if we think about the various deficiencies a student impinge during his academic formation, which is excessively centered on technical aspects, with incipient training in the clinical area. ${ }^{8}$ School Institutions are important sources of reference and generate knowledge, with representativeness within the social and scientific community. Thus, underdevelopment in these areas deprives not only the scientific community but also the population in general of the refinement and development of new policies and technologies related to the health area, considering the potential for application of the knowledge generated to the society.

According to the OPAS and the Health Ministry, the participation of the pharmacist in internal committees is part of the competence of HP established by resolution 308/97. ${ }^{9}$ The Pharmacy and Therapeutics Committees is one of the most relevant since it acts as a consultation, coordination and information, organ regarding medications, with the participation of the pharmacist, being essential in order to guarantee the Rational Use of Medication. The contribution of the pharmacy to the control of hospital infections is considered to be essential by the American Society of Health-System Pharmacists (ASHP), the organ responsible for the establishment of the standards to be followed by pharmacists in the actions for the control of hospital infections. ${ }^{10}$ The participation of the pharmacist in the Nutritional Support Committee is also essential for the success of nutritional therapy, since, as the only manipulator, he has in-depth knowledge about all the pharmacological and therapeutic characteristics of the elements involved in the nutritional scheme. Thus, the participation of the pharmacist in these activities is imperative since these activities represent essential elements of an HP. He also should implement other activities such as programs of pharmacovigilance, pharmacoepidemiologic studies, elaboration of pharmacotherapeutic protocols and pharmacoeconomic evaluations. ${ }^{11}$

Still according to the OPAS and the Health Ministry, the implantation of a system of information about medications is considered a fundamental function of the HP'. Besides making available objective data that permit the health team to prescribe and administer medications under conditions of better technical safety, this system also provide orientation both to the patient at the time of dis- charge or in the ambulatory treatments and to the entire hospital community. The Pharmacotherapeutic follow-up, by being one of the main components of Pharmaceutical Care, represent the process by which the pharmacist is responsible for the necessities of the user related to the medication, by detecting, preventing and solving Problems Related to Medication (PRM) in a systematic, continuous and documented manner in order to achieve defined results in an attempt to improve the quality of life of the user. ${ }^{12}$ The lack of clinical activities and of a qualified structure in the sector of information about medications creates a distance between the professional and the clinical staff in terms of a more effective participation, impairing the inclusion of a new professional practice directed at patient care. Several studies indicate that multiprofessional work is essential in order to fulfill both the clinical and therapeutic objectives. An investigation conducted in clinics in the city of Minneapolis (MN, USA) in order to evaluate the joint action of pharmacists and physicians regarding the reduction of morbidity related to the use of medications, which impairs the objectives of the treatment applied, detected a total of 5780 PRMs, of these, were resolved 2524 with patients receiving pharmaceutical care. And the rate of achievement of the objectives with the therapy used increased $74 \%$ during the initial stages of monitoring and $89 \%$ in the final phase, demonstrating the efficiency of clinical care associated with therapy. ${ }^{13}$

One of the main professional functions of the hospital pharmacist is the dispensing of medications. Even when a positive index is obtained regarding the evaluation of medical prescriptions, the evaluation must be performed in a more in-depth manner in pharmacological terms since, in addition to being the only professional qualified to evaluate a medical prescription because of his specialized training, the pharmacist is also more skilled in the detection of errors. ${ }^{14,15}$

Although management activities require a large part of the working time of these professionals, the questions related to logistics and considered to be essential for a good performance of this service are under the responsibility of only a small group.

The great challenge of material administration is the correct dimensioning of stocks. It is necessary to maintain a stock level that will satisfy the necessities of the hospital, with regular supplies. An efficient control is also necessary, with the use of adequate instruments. As observed in the present study, these tools (curve $\mathrm{ABC}$, spreadsheets) were little used, a fact that limits a closer and more effective stock control.

Nevertheless, the Pharmacy Division contemplated the execution of various activities within the Hospital 
Pharmacotechnique. Despite the good performance shown, not all sectors adopted measures of quality control, actions that are essential as safety measures both for the patient and for the manipulating professional.

Delineated like this, the current situation of the Hospital Pharmacy Service, both in its operational and human aspects, it is hoped that the present results will serve as parameters and act as a comparative effect for evaluation or as the basis of discussion about changes within the administrative and personal process. Changes that could be those suggested by the researchers or that could occur by means of agreements between the members of the Pharmacy staff and the direction of the Hospital.

\section{CONCLUSION}

The Pharmacy Division of the Hospital under study offers a wide variety of services considered to be essential for the good development of a hospital pharmacy, such as the preparation of Parenteral Nutrition, Chemotherapeutic Medications, and internal Production of Medications.

Important services, such as the Service of Information about Medications only functioned in an informal manner and others, such as Teaching and Research activities, could be improved.
The participation in internal committees was characterized more by a connotation of obligation than of contribution and improvement of services.

In addition, the pharmacy has a work logic centered on medication, with few advances demonstrating a change in this picture.

Finally, based on the results, changes are needed to improve the sector, which must prioritize a reformulation of the management of the services, with reorganization of the human resources.

Barner and Bennett (1999) ${ }^{16}$ stated that the direct investment in qualification of the professional brings positive results according to a project developed by them, i.e., a Pharmaceutical Care Certificate Program (PCCP), a program of certification and update with training, developed by the Pharmacy College of the University of Texas. After one year of preparation, the participating pharmacists felt that they were better prepared for practice pharmaceutical activities.

Thus, for the improvement of the sector, the investment in professional qualification becomes essential, in addition to stimulation of the development of activities directed at practice clinical care with increase of the attention returned to the patient.

\section{RESUMO}

Penaforte TR, Forster AC, Silva MJS. Avaliação da Atuação dos Farmacêuticos na Prestação da Assistência a Saúde em um Hospital Universitário. Clinics. 2007; 62(5):56772.

OBEJTIVO: O propósito deste estudo foi avaliar as práticas dos farmacêuticos em um hospital, na realização da Assistência Hospitalar.

MÉTODO: foram entrevistados 20 farmacêuticos da Divisão de Farmácia, sendo aplicado um instrumento estruturado, em setembro de 2005. Esse instrumento abordou aspectos relativos às principais atividades da Farmácia Hospitalar, que foram avaliadas segundo indicadores organizados em cinco áreas: gerenciamento das unidades, farmacotécnica hospitalar, atividades em comissões, informação e seguimento Farmacoterapêutico, e, atividades de ensino e pesquisa.

RESULTADOS: A Divisão de Farmácia contemplou todos os aspectos estruturais considerados como essenciais para o bom desenvolvimento e aplicação de seus serviços. Verificou-se a ausência de alguns serviços essenciais como o Serviço de Informação de Medicamentos e de Seguimento Farmacoterapêutico. Os profissionais farmacêuticos encontravam-se insatisfeitos quanto ao dimensionamento dos recursos humanos e à estrutura física, e se demonstram pouco atuantes em relação à Assistência Farmacêutica.

CONCLUSÃO: Os resultados indicaram uma atenção ainda centralizada no medicamento, com poucas atividades clínicas. Sugerem-se reformulações no gerenciamento dos serviços com ênfase na administração dos farmacêuticos.

UNITERMOS: Serviço de Farmácia Hospitalar. Avaliação de Processos e Resultados (Cuidados de Saúde). Administração de Recursos Humanos em Hospitais. Qualidade da Assistência à saúde. Farmacêutico Hospitalar. 
1. Wilken PRC, Bermudez, JAZ. A Farmácia do Hospitalar: como avaliar? Rio de Janeiro: Agora da Ilha; 1999.

2. Cavalini ME, Bisson MP. Farmácia Hospitalar um enfoque em sistemas de saúde. 1 ed. Barueri, São Paulo: Manole; 2002.

3. Novaes HMD. Avaliação de programas, serviços e tecnologias em saúde. Rev. Saúde Pública. 2000;34:547-59.

4. Donabedian A. The criteria and standards of quality. Ann Harbor, Health Administration Press; 1982. v. 2.

5. Patton MQ . Qualitative evaluation and research methods. London: Sage Publications; 1990.

6. Westphal MF (org), Almeida ES (org). Gestão de Serviços de Saúde: Descentralização, Municipalização do SUS. São Paulo: Edusp; 2001. p. 274.

7. Dunlop JA, Shaw JP. Community pharmacists' perspectives on pharmaceutical care implementation in New Zealand. Pharmacy World Sci. 2002;24:224-30.

8. Osório-de-Castro CGS (org), Castilho SR (org). Diagnóstico da Farmácia Hospitalar no Brasil. Rio de Janeiro: Ensp/Fiocruz; 2004.

9. Rosa MB. Farmácia Hospitalar: histórico, conceito, objetivos, atribuições, perfil do farmacêutico. In: CONSELHO FEDERAL DE FARMÁCIA. Manual Básico de Farmácia Hospitalar. Brasília; 1997.
10. Cipriano SL. Proposta de um conjunto de indicadores para utilização na Farmácia Hospitalar com foco na Acreditação Hospitalar. 2004. Dissertação de Mestrado - Faculdade de Saúde Pública, Universidade de São Paulo, São Paulo.

11. Organización Panamericana de Salud. El papel de Farmacéutico en el sistema de atención de Salud - Buenas Prácticas de Farmacia: Normas de Calidad de Servicios Farmacéuticos. Tokio; 1993. (Informe de La Reunión de la OMS)

12. Organização Pan-Americana de Saúde. Consenso Brasileiro de Atenção Farmacêutica: Proposta Brasília. 2002.

13. Organización Mundial de La Salud. El papel del Farmacéutico en el Sistema de Atención de Salud - Programa de Acción de Medicamentos Esenciales y Unidad Farmacéutica. Nueva Delhi; 1990. (Informe de un grupo de consulta de la OMS)

14. ASHP guidelines on preventing medication errors in hospitals. Am J Hosp Pharm. 1993;50:305-314.

15. Isetts BJ, Brown LM, Schondelmeyer SW, Lenarz LA. Quality assessment of a collaborative approach for decreasing drug-related morbidity and achieving therapeutic goals. Arch Intern Med (Archives of internal medicine). 2003;163:1813-20.

16. Barner JC, Bennett RW. Pharmaceutical care certificate program: assessment of pharmacists' implementation into practice. J Am Pharm Assoc (Wash).1999;39:362-7 